\title{
Production of Biodiesel from Lipid of Porphyridium cruentum through Ultrasonic Method
}

\author{
Raymond Kwangdinata, Indah Raya, and Muhammad Zakir \\ Chemistry Department, Faculty of Mathematics and Natural Sciences, Hasanuddin University, Makassar 90245, Indonesia \\ Correspondence should be addressed to Indah Raya; indahraya05@gmail.com
}

Received 17 January 2014; Accepted 18 February 2014; Published 10 March 2014

Academic Editors: T. M. I. Mahlia and J. Zhang

Copyright ( 2014 Raymond Kwangdinata et al. This is an open access article distributed under the Creative Commons Attribution License, which permits unrestricted use, distribution, and reproduction in any medium, provided the original work is properly cited.

\begin{abstract}
A research on production of biodiesel from lipid of phytoplankton Porphyridium cruentum through ultrasonic method has been done. In this research, we carried out a series of phytoplankton cultures to determine the optimum time of growth and biodiesel synthesis process from phytoplankton lipids. Process of biodiesel synthesis consists of two steps, that is, isolation of phytoplankton lipids and biodiesel synthesis from those lipids. Oil isolation process was carried out by ultrasonic extraction method using ethanol $96 \%$, while biodiesel synthesis was carried out by transesterification reaction using methanol and $\mathrm{KOH}$ catalyst under sonication. Weight of biodiesel yield per biomass Porphyridium cruentum is $40,27 \%$. Characterization of biodiesel was well carried out in terms of physical properties which are density and viscosity and chemical properties which are FFA content, saponification value, and iodine value. These values meet the American Society for Testing and Materials (ASTM D6751) standard levels, except for the density value which was $0.9461 \mathrm{~g} \cdot \mathrm{cm}^{-3}$ and the FFA content which was $4.6671 \%$.
\end{abstract}

\section{Introduction}

That energy crisis is attacking the world today is a problem that must be resolved and addressed. The continuous exploitation of the fossil fuels which are nonrenewable energy resulted in dwindling existence. This will have an impact on the scarcity of fossil fuels, thereby increasing the price of fuel oil (BBM) world. This situation has made most of the countries in the world (one of them is Indonesia) seek sources of alternative fuel that can be developed from other basic materials that are renewable and environmentally friendly [1]. Therefore, to meet the level of oil consumption and encourage the development and utilization of renewable alternative energy, biofuels 1 (biofuels) such as biodiesel can be used [2].

Earth is mostly composed of water environment which is rich of potential renewable resources, especially in Indonesian waters. Indonesia has the chance of being the biofuels producing country as we know that Indonesia has the immense of the natural capital, especially the environmental water.

Indonesia is an archipelago with two-thirds of the area being the sea and the longest coastline in the world, which is $80,791.42 \mathrm{~km}$, and is rich in aquatic biological resources, which are very abundant in both kind and quantity. One of Indonesia's natural potential is microalgae or phytoplankton, which can be used as an alternative source of biodiesel, because it contains lipid, in addition to protein, carbohydrates, and vitamins. The lipid content which is contained in phytoplankton will be converted into biodiesel [3].

Advantages of the phytoplankton are the rapid growth rate and high productivity. Phytoplankton or microalgae can produce biomass 50 times more likely than other higher plants [4], in addition to the land competition with other plants are relatively do not happen because the various types of microalgae could live in different types of environments even in areas with limited land. Microalgae can live almost anywhere that has enough sunlight, water, and $\mathrm{CO}_{2}[5]$.

Research on microalgae as a raw material of biodiesel, especially marine phytoplankton, has been carried out. However, research on the culture of phytoplankton that produced lipids for biodiesel used as base material is still less common, particularly marine phytoplankton Porphyridium cruentum.

In microalgae, lipids have as a basic function the synthesis of lipoprotein membranes and are important in floating 
and as an energetic reserve. Accumulation of lipids can be attributed to consumption of sugar at a rate higher than the rate of cell generation, which would promote conversion of excess sugar into lipids. The lipids extracted from microalgae may be used in human nutrition as source of omega-3. Accumulation of lipids in the microalgae cells, as well as for other oleaginous microorganisms (high oil producers), depends on diverse factors, such as growth temperature, $\mathrm{pH}$, availability of micronutrients, salinity, and other factors [6].

Marine phytoplankton Porphyridium cruentum has a fairly high fat content which is equal to 9.0 to $18.8 \%$ dry weight biomass; phytoplankton species can reach the fat content of $60.7 \%$ of the dry weight in certain conditions (stress) [5].

The commercial production of microalgae derived biodiesel is still in the research and developmental stages, mainly due to the current prohibitive high costs associated with the biomass production and fuel conversion process [7]. Different studies showed that the harvesting cost of algal production in open ponds accounts for more than $20-30 \%$ of the total cost of biodiesel production [8]. Many separation methods, such as centrifugation, gravity sedimentation, (ultra) filtration and screening, flocculation, flotation, and ultrasound waves, have been developed for microalgae recovery.

However, each method has its disadvantages that affect the overall economics of the process. Centrifugation requires high energy input and initial capital cost [9] and the process involves exposing cells to high gravitational and shear forces which damage the cell structure. Second, the processing of large culture volumes can be time consuming [10]. Filtration and screening require regular replacement of filters, screens, and membranes and can be very time consuming. Gravity sedimentation is a low process and electroflotation requires replacement of worn electrodes that have been consumed and a high cost of electricity $[9,11]$. Thus, to minimize the energy consumption of harvesting microalgae, an integrated approach is needed [12].

The alternate use of the one-step in situ transesterification method for biodiesel production has been discussed to potentially lead to the reduction of the energetic, raw material, and economic process requirements when compared to the use of the conventional oil extraction and transesterification process [13]. To achieve that goal, this research uses the low frequency ultrasound and the addition of alkaline catalyst for the in situ transesterification of microalgae biomass.

The main problem in the biodiesel production process is that alcohol and oil as the main raw materials are not intermingled (immiscible) [14]. The application of ultrasonic stirring to improve transesterification yields and reduce reaction times has been reported in the literature for the conventional alkaline transesterification of various extracted biomass oil $[15,16]$. This is due to the possibility for increased mass transfer between the immiscible liquid phases. The oilalcohol phase boundary was reported to be disrupted due to the collapse of ultrasonically induced cavitation bubbles, in turn, leading to an accelerated alkyl ester formation [16]. Stirring is a technique commonly used so that alcohol and oil can be mixed with each other so that the reaction can be run up to the formation of biodiesel, but mixing requires a relatively large energy [14].

From several studies that have been conducted, the use of ultrasonic waves has proven to accelerate the reaction, reducing the amount of catalyst used and reducing the ratio of oil to alcohol use than the reaction without the help of ultrasonic waves. This is due to the fact that ultrasonic wave energy arises from acoustic cavitation process (acoustic cavitation) which consists of the formation, growth, and collapse (implosive collapse) of the bubble formed. Ultrasonic waves cause the mechanical effects on the reaction, for example enlarge the surface area through microgap formation on the surface, accelerating dissolution, or increase the rate of mass transfer [17-19].

\section{Materials and Methods}

2.1. Materials. The materials used in this research work include phytoplankton cultures derived from Porphyridium cruentum, which is obtained from Bioinorganic Chemistry Laboratory Hasanuddin University, ocean water from coastal area of Makassar sterilized and distilled water, sodium borax, $\mathrm{FeCl}_{2} \cdot 6 \mathrm{H}_{2} \mathrm{O}, \mathrm{MnCl}_{2} \cdot 4 \mathrm{H}_{2} \mathrm{O}, \mathrm{H}_{3} \mathrm{BO}_{3}, \mathrm{Na}_{2}$ EDTA, $\mathrm{NaH}_{2} \mathrm{PO}_{4} \cdot 2 \mathrm{H}_{2} \mathrm{O}, \mathrm{NaNO}_{3}, \mathrm{ZnCl}_{2}, \mathrm{CoCl}_{2} \cdot 6 \mathrm{H}_{2} \mathrm{O}, \mathrm{CuSO}_{4}$. $5 \mathrm{H}_{2} \mathrm{O},\left(\mathrm{NH}_{4}\right)_{6} \mathrm{Mo}_{7} \mathrm{O}_{24} \cdot 4 \mathrm{H}_{2} \mathrm{O}$, vitamin $\mathrm{B} 12$, vitamin $\mathrm{B} 1, \mathrm{KIO}_{3}$, $\mathrm{H}_{2} \mathrm{SO}_{4}$, potassium iodide, methanol pa, potassium hydroxide, $\mathrm{HCl}, \mathrm{Na}_{2} \mathrm{~S}_{2} \mathrm{O}_{3} \cdot 5 \mathrm{H}_{2} \mathrm{O}$, anhydrous $\mathrm{Na}_{2} \mathrm{SO}_{4}$, oxalic acid, phenolphthalein indicator, indicator methyl orange, $96 \%$ ethanol, iodine $\left(\mathrm{I}_{2}\right)$, starch, filter paper, label paper, and aluminum foil.

2.2. Apparatus. The apparatus used in this research work includes glass tools which are generally used in the laboratory, jars made of cover glass, aerator, salinometer, centrifuge, haemocytometer, Japan Nikon microscopes SE Model Type 102, Olympus microscope SZX16, desiccators, pumps vacuum, Buchner funnel, water bath, Buchi rotary evaporator, blower, Oswald viscometer, burette $50 \mathrm{~mL}$ Pyrex, analytical balance, and ultrasonic equipment S $40 \mathrm{H}$ Elmasonic.

\subsection{Work Procedures}

2.3.1. Culture of Phytoplankton. Porphyridium cruentum, obtained from Bioinorganic Chemistry Laboratory Hasanuddin University, was grown in sterile Conway's medium where it was conditioned with aeration process $\mathrm{CO}_{2}$ gas. The filtered sterilized seawater was enriched with Conway's medium containing $\mathrm{FeCl}_{2} \cdot 6 \mathrm{H}_{2} \mathrm{O}, \mathrm{MnCl}_{2} \cdot 4 \mathrm{H}_{2} \mathrm{O}, \mathrm{H}_{3} \mathrm{BO}_{3}$, $\mathrm{Na}_{2}$ EDTA, $\mathrm{NaH}_{2} \mathrm{PO}_{4} \cdot 2 \mathrm{H}_{2} \mathrm{O}, \mathrm{NaNO}_{3}, \mathrm{ZnCl}_{2}, \mathrm{CoCl}_{2} \cdot 6 \mathrm{H}_{2} \mathrm{O}$, $\mathrm{CuSO}_{4} \cdot 5 \mathrm{H}_{2} \mathrm{O},\left(\mathrm{NH}_{4}\right)_{6} \mathrm{Mo}_{7} \mathrm{O}_{24} \cdot 4 \mathrm{H}_{2} \mathrm{O}$, vitamin $\mathrm{B} 12$, and vitamin $\mathrm{B} 1$. The medium was adjusted to salinity $30 \%$ and temperature $30^{\circ} \mathrm{C}$. After that, density of phytoplankton is calculated.

2.3.2. Determinate Time of Phytoplankton Growth. Determination of phytoplankton growth pattern is done through counting the number of cells per milliliter of medium every 24 hours. Samples are taken with a sterile pipette, dropped 
about $0.1-0.5 \mathrm{~mL}$ on haemocytometer, and then observed through a microscope [20].

2.3.3. Isolation of Phytoplankton Lipid. Marine phytoplankton Porphyridium cruentum was dried in the oven, placed in Erlenmeyer, added with $96 \%$ ethanol, with a ratio of $1: 6 \mathrm{w} / \mathrm{v}$, and then extracted by means of an ultrasonic cleaner that operated at a frequency of $40 \mathrm{kHz}$. Ethanol extract was containing lipids that were separated by using a rotary evaporator.

2.3.4. Synthesis Biodiesel through Ultrasonic Method. Pure lipids from marine phytoplankton Porphyridium cruentum already are obtained, inserted into the Erlenmeyer, and heated in an ultrasonic cleaner tool which is operated at a frequency of $40 \mathrm{kHz}$ and a temperature of $50-60^{\circ} \mathrm{C}$ and then mixed with a solution made of methanol (mole ratio of lipid : methanol is $1: 12$ ) and $\mathrm{KOH}$ catalyst (9\% lipid content) that has been stirred for 15 minutes. Time for the transesterification process was about 180 minutes. While the reaction was taking place, the heating temperature should be maintained. Furthermore, the results of the transesterification were left for 3-4 days to form two phases. Then it was separated and followed by the addition of anhydrous $\mathrm{Na}_{2} \mathrm{SO}_{4}$ to the methyl ester to pull the rest of the water in the solution. The next stage was to separate $\mathrm{Na}_{2} \mathrm{SO}_{4}$ from biodiesel by using centrifuges. Supernatant in the form of methyl esters (biodiesel) was taken and then heated in an oven at a temperature of $70^{\circ} \mathrm{C}$. Subsequently the physical and chemical properties of the obtained pure biodiesel were then analyzed to determine the quality of the biodiesel.

2.3.5. Analysis of Physical Properties. Analyses of the physical properties are density and viscosity. Density analysis procedures were carried out by the method ASTM D1475 and viscosity analyses were carried out by the method ASTM D445.

2.3.6. Analysis of Chemical Properties. Analyses of the chemical properties are content of free fatty acid (\% FFA), saponification value, and iodine value. Procedures of free fatty acids (\% FFA) were based on the AOCS method Ca 5a-40, saponification value was based on AOCS method Cd 3-25, and value iodine was based on Wijs method.

\section{Results and Discussions}

3.1. The Growth Pattern of Marine Phytoplankton Chaetoceros calcitrans. Observations of marine phytoplankton growth pattern Chaetoceros calcitrans were done every 24 hours for 17 days by using the Conway medium as growth media in sterile seawater salinity adjusted and accompanied by the addition of vitamins to the media. The chart patterns of phytoplankton growth Porphyridium cruentum are shown in Figure 1.

Based on Figure 1, it could be seen that from day 1 till day 2 there was a phase of adaptation for phytoplankton Porphyridium cruentum to the growth medium. Later from day 3 to day 10 Porphyridium cruentum experienced a very rapid

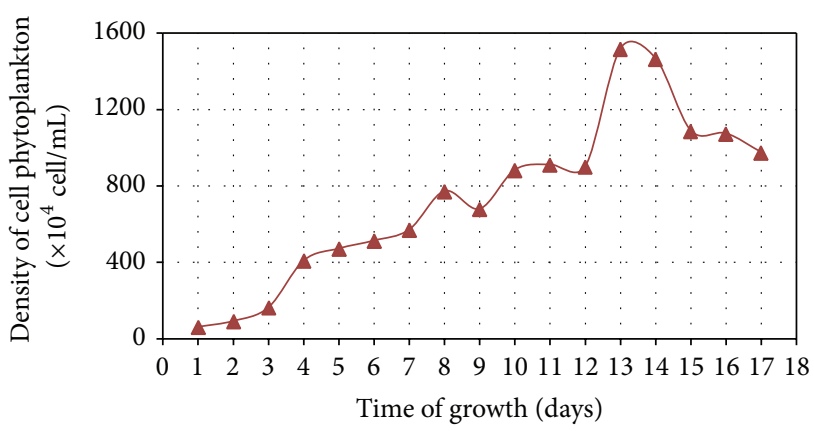

FIgure 1: Chart patterns of marine phytoplankton growth Porphyridium cruentum.

increase in population, known as the exponential phase. Furthermore, at the stationary phase, the growth of rate began to slow down, which occurred from day 10 to day 13, unlike the previous days, which occurred from day 3 to day 10 . Then on day 13 until day 17 a decline of phytoplankton populations Porphyridium cruentum started. This phase is the phase where a decline in population mortality or decreased growth rate of phytoplankton occurs. Time optimal phytoplankton growth can be seen from the highest cell density of Porphyridium cruentum, $1520.9375 \times 10^{4}$ cells $/ \mathrm{mL}$, which occurred on day 13.

3.2. Production of Dry Biomass. Total biomass of phytoplankton Porphyridium cruentum from cultures is 67.2953 grams, so that production of dry concentration weight was $5,3836 \mathrm{~g} / \mathrm{L}$. The dry concentration weight of Chlorella sp. was $1.9 \mathrm{~g} / \mathrm{L}$ [21], Botryococcus braunii was $3.5 \mathrm{~g} / \mathrm{L}$ [22], and Picochlorum sp. was $2.4 \mathrm{~g} / \mathrm{L}$ [23]. Based on data, the higher biomass productivity was Porphyridium cruentum than other microalgae like Chlorella sp., Botryococcus braunii, and Picochlorum sp. This is due to the fact that the size of microalgae is different. The main goals of microalgae biodiesel production are high lipid yield and high biomass productivity which can affect production costs.

3.3. Isolation Lipid of Phytoplankton Porphyridium cruentum. An early stage of biodiesel production from phytoplankton was isolation lipid of phytoplankton Porphyridium cruentum using ultrasonic extraction method. At this stage, solvent ethanol $96 \%$ is used. In this phase, the ultrasonic method plays an important role to destroy the cell wall composition of phytoplankton so that the function of ethanol will be more efficient in extracting lipids because it has the same polarity as the material to be extracted. Samples of dry biomass of phytoplankton Porphyridium cruentum at 67.2953 grams were extracted with $96 \%$ ethanol; extraction time was 9 hours and 10 minutes. The time is needed for extraction to belong a long time because the difficulty of cell wall damage.

The result of extraction in the form of lipids which dissolved in $96 \%$ ethanol was separated from its solvent by evaporating all ethanol $96 \%$ was used separately in order to obtain the pure lipid that can be seen in Figure 2(a). Lipid weight of Porphyridium cruentum was 15, 2273 gram obtained 


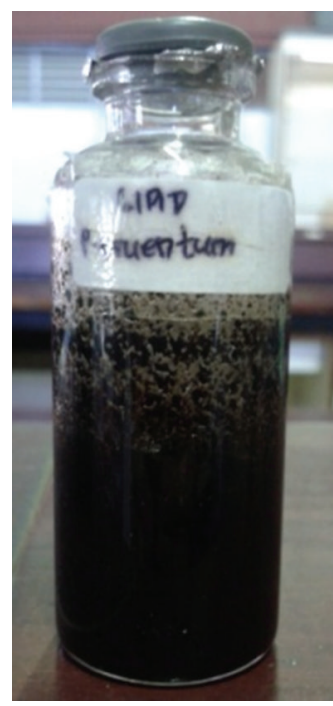

(a)

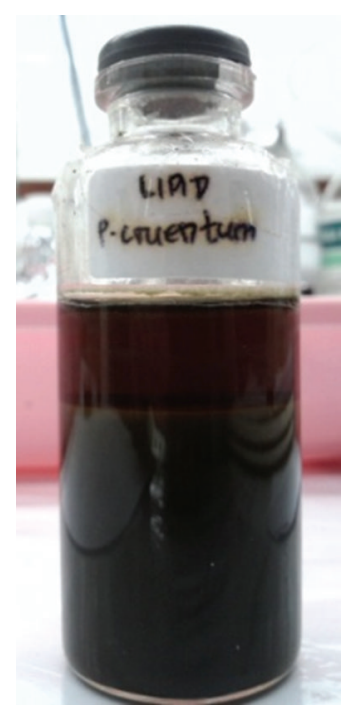

(b)

Figure 2: (a) Lipid of phytoplankton Porphyridium cruentum. (b) Result of transesterification reaction.

so that the lipid content was $22.6276 \%$ of biomass dry weight. Lipid content obtained from the phytoplankton species does not reach $50 \%$ of the dry biomass.

Lipid productivity of Porphyridium cruentum from this research was $0.2263 \mathrm{~g} / \mathrm{g}$ DCW, whereas lipid productivity of Chlorella sp., Botryococcus braunii, and Picochlorum sp. was $0.10-48.0 \mathrm{~g} / \mathrm{g}$ DCW, $0.45 \mathrm{~g} / \mathrm{g}$ DCW, and $0.0861 \mathrm{~g} / \mathrm{g} \mathrm{DCW}$, respectively $[4,23]$. This is due to the fact that phytoplankton does contain not only lipids but also carbohydrates and protein.

However, how to select the microalga species and what was the criterion for the good oil-producing species also puzzled many scientists in the world, as there is still no criterion for the selection process at present. According to this research in microalgae-based biofuel research, the expected candidate oil producers should satisfy the following requirements: high growth rate, high cell density at the end of stationary growth stage, high total lipid content, and high lipid productivity.

3.4. Synthesis Biodiesel from Phytoplankton Lipid. Synthesis biodiesel from phytoplankton lipid was done by transesterification using methanol $(1: 12)$. It was accelerated by the addition of $\mathrm{KOH}$ alkaline catalyst ( $9 \%$ lipid content). Time of transesterification reaction was around 180 minutes with a heating temperature of $50-60^{\circ} \mathrm{C}$ using an ultrasonic cleaner tool which is operated at a frequency of $40 \mathrm{kHz}$. Then the reaction was left for 3-4 days to form two layers. The top layer was a layer of green biodiesel murky orange, while the bottom layer is a layer of glycerol golden brown, which can be seen in Figure 2(b).

Having obtained the two layers, the upper and lower layers were separated. The top layer was then centrifuged to remove impurities and glycerol which may end up at the time of separation. The remaining methanol in the biodiesel that does not react was removed by heating in an oven at a

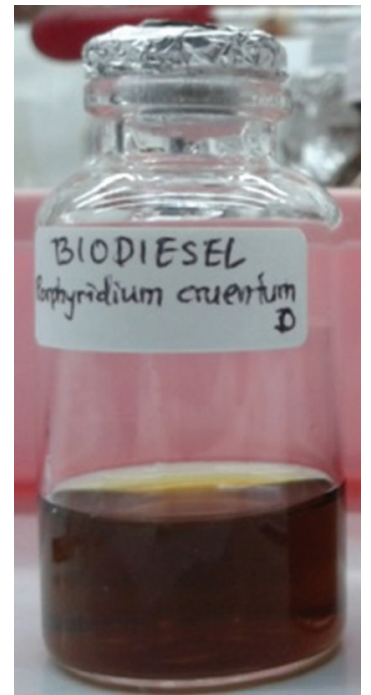

Figure 3: Biodiesel of phytoplankton Porphyridium cruentum.

temperature of $70^{\circ} \mathrm{C}$. Subsequently obtained pure biodiesel can be seen in Figure 3.

Weight of biodiesel is produced 27.0953 gram with yield $40.27 \%$. This is due to the fact that the fatty acids in the lipid component of phytoplankton have not reacted completely with methoxy ions in the transesterification reaction. Factors that could cause this are the temperature and reaction time which are not optimal. Biodiesel produced from phytoplankton also has a characteristic of red-orange color.

3.5. Analysis of Physical Properties. The next stage of the synthesis results of obtaining biodiesel from lipids phytoplankton Porphyridium cruentum through transesterification reaction was carried out, the characterization of physical 
TABLE 1: Result of density and viscosity analysis.

\begin{tabular}{lccc}
\hline & Density $\left(\mathrm{g} \cdot \mathrm{cm}^{-3}\right)$ & & Viscosity (cSt) \\
Result of research & Standard ASTM D6751 & Result of research & Standard ASTM D6751 \\
\hline 0.9461 & $0.82-0.90$ & 3.47 & $1.60-5.80$ \\
\hline
\end{tabular}

TABLE 2: Results of analysis of free fatty acid (\% FFA), saponification value, and iodine value.

\begin{tabular}{lcc}
\hline Analysis & Result of research & Standard ASTM D6751 \\
\hline Free fatty acid content $(\% \mathrm{FFA})$ & 4.6671 & $<0.45$ \\
Saponification value $(\mathrm{mg} \mathrm{KOH} / \mathrm{g})$ & 140.1628 & $<500$ \\
Iodine value $\left(\mathrm{g} \mathrm{I}_{2} / 100 \mathrm{~g}\right)$ & 13.1569 & $<115$ \\
\hline
\end{tabular}

properties based on the standard ASTM D6751. The test's physical properties of biodiesel include analysis of density and viscosity. Density and viscosity analysis results can be seen in Table 1.

3.5.1. Density Analysis. Biodiesel produced from lipid phytoplankton Porphyridium cruentum has a density value which was $0.9461 \mathrm{~g} \cdot \mathrm{cm}^{-3}$ at a temperature of $40^{\circ} \mathrm{C}$. The default value of $40^{\circ} \mathrm{C}$ density specified in ASTM D6751 is 0.82 to $0.90 \mathrm{~g} \cdot \mathrm{cm}^{-3}$. Density is one determinant of the quality of biodiesel as it pertains to the value of the generated heat and power diesel engines. The lower the value of the density is, the higher the heating value or combustion will be [24].

When compared to the standard ASTM D6751, the biodiesel from the phytoplankton species can be said to be not included in the range of density values that have been set.

3.5.2. Viscosity Analysis. Viscosity is one of the standards in determining the quality of biodiesel and has a very important role in the process of fuel reinjection. Low viscosity value can lead to leakage of fuel injection pump and if it is too high, it can affect the work quickly and make carburetion injector fuel [24].

The result of kinematic viscosity that was obtained in this research work was $3.47 \mathrm{cSt}$ where the value that included the standard value of kinematic viscosity range which is recommended in ASTM D6751 is equal to 1.60 to $5.80 \mathrm{cSt}$.

3.6. Analysis of Chemical Properties. Characterization of the chemical properties test was based on ASTM D6751 biodiesel made after the physical properties test is completed. The chemical properties of biodiesel test include the analysis of free fatty acid content (\% FFA), saponification value, and iodine value. Results of analysis of free fatty acid (\% FFA), saponification value, and iodine value can be seen in Table 2 .

3.6.1. Analysis of Free Fatty Acid Content (\% FFA). Free fatty acid value of biodiesel results of this research in which the value of $4.6671 \%$ exceeded the standard levels of free fatty acids/FFA (\%) biodiesel recommended in ASTM D6751 is $0.45 \%$. The high levels of free fatty acids that can cause deposition in combustion systems are also an indicator that the fuel can serve as a solvent which can lead to a reduction in the quality of the fuel system. High free fatty acids may also reduce the life of the pump and filter. The higher the free fatty acids are, the lower the quality of diesel fuel will be.

3.6.2. Analysis of Saponification Value. The saponification number is defined as the milligrams of $\mathrm{KOH}$ required to neutralize one gram sample lipid or oil. The lower the molecular weight is, the higher the saponification number will be, and vice versa [25].

Saponification value results obtained in this research are $140.1628 \mathrm{mg} \mathrm{KOH} / \mathrm{g}$ where the value which is smaller than the standard value of saponification value in ASTM D6751 is less than $500 \mathrm{mg} \mathrm{KOH} / \mathrm{g}$. Based on these data biodiesel from Porphyridium cruentum phytoplankton species has a low saponification number and enters the biodiesel quality control set by ASTM D6751.

3.6.3. Analysis of Iodine Value. Iodine numbers in biodiesel showed unsaturation level of the building blocks of biodiesel. On the one hand, the presence of unsaturated fatty compounds improves the performance of biodiesel at low temperatures because this compound has a melting point that correlated with a lower cloud point and a pouring point that was also low [26].

Biodiesel produced from lipid phytoplankton Porphyridium cruentum has iodine number which was $13.1569 \mathrm{~g}$ $\mathrm{I}_{2} / 100 \mathrm{~g}$ which met the quality standards iodine number in ASTM D6751 is less than $115 \mathrm{~g} \mathrm{I}_{2} / 100 \mathrm{~g}$.

Biodiesel with high iodine numbers will produce esters with the flow and solidification at low temperature. Biodiesel which has a higher degree of unsaturation is not suitable for use as biodiesel because unsaturated molecules will react with oxygen from the atmosphere, which will be converted into peroxide crosslinking, result in the unsaturated, and cause the polymerized biodiesel to form a similar plastic material, especially if the temperature increases. As a result, the diesel engine will not work properly and will be damaged [27].

\section{Conclusion}

Lipid phytoplankton Porphyridium cruentum can be isolated by ultrasonic extraction wherein the lipid content of Porphyridium cruentum is equal to $22.6276 \%$ of biomass dry weight. Quantity of biodiesel synthesized from lipid phytoplankton Porphyridium cruentum through the ultrasonic 
method is equal to 27.0983 gram with yield $40.27 \%$. Quality of biodiesel from phytoplankton Porphyridium cruentum mostly had yet to meet the ASTM D6751 standard American Society for Testing and Materials (ASTM D6751). The parameter which is not met is the value of density and free fatty acid content.

\section{Conflict of Interests}

The authors declare that there is no conflict of interests regarding the publication of this paper.

\section{References}

[1] K. Triantoro, "Microalgae scenedesmus sp. as one alternative of raw materials biodiesel in Indonesia," Scientific Paper, Faculty of Mathematics and Natural Sciences, State University of Yogyakarta, Yogyakarta, Indonesia, 2008.

[2] O. Rachmaniah, R. D. Setyarini, and L. Maulida, "Selection of algae oil extraction method of chlorella sp. and predictions for biodiesel production," in Seminar of Chemical Engineering Soehadi Reksowardojo, Department of Chemical Engineering, Faculty of Industrial Technology, Tenth of November Institute of Technology, Surabaya, Indonesia, 2010.

[3] E. R. Yosta, D. W. Harimurti, and O. Rachmaniah, Preliminary Study: Extraction of Algae Oil from Spirulina sp. as the New Discourse of Raw Material Alternative on Process of Biodiesel Production, Tenth of November Institute of Technology, Surabaya, Indonesia, 2009.

[4] Y. Li, M. Horsman, N. Wu, C. Q. Lan, and N. Dubois-Calero, "Biofuels from microalgae," Biotechnology Progress, vol. 24, no. 4, pp. 815-820, 2008.

[5] T. M. Mata, A. A. Martins, and N. S. Caetano, "Microalgae for biodiesel production and other applications: a review," Renewable and Sustainable Energy Reviews, vol. 14, no. 1, pp. 217232, 2010.

[6] G. S. Araujo, L. J. B. L. Matos, L. R. B. Gonçalves, F. A. N. Fernandes, and W. R. L. Farias, "Bioprospecting for oil producing microalgal strains: evaluation of oil and biomass production for ten microalgal strains," Bioresource Technology, vol. 102, no. 8, pp. 5248-5250, 2011.

[7] E. A. Ehimen, Z. F. Sun, and C. G. Carrington, "Variables affecting the in situ transesterification of microalgae lipids," Fuel, vol. 89, no. 3, pp. 677-684, 2010.

[8] S. Salim, R. Bosma, M. H. Vermuë, and R. H. Wijffels, "Harvesting of microalgae by bio-flocculation," Journal of Applied Phycology, vol. 23, no. 5, pp. 849-855, 2011.

[9] N. Uduman, Y. Qi, M. K. Danquah, and A. F. A. Hoadley, "Marine microalgae flocculation and focused beam reflectance measurement," Chemical Engineering Journal, vol. 162, no. 3, pp. 935-940, 2010.

[10] A. Papazi, P. Makridis, and P. Divanach, "Harvesting Chlorella minutissima using cell coagulants," Journal of Applied Phycology, vol. 22, no. 3, pp. 349-355, 2010.

[11] D. Vandamme, I. Foubert, B. Meesschaert, and K. Muylaert, "Flocculation of microalgae using cationic starch," Journal of Applied Phycology, vol. 22, no. 4, pp. 525-530, 2010.

[12] J. R. Benemann, " $\mathrm{CO}_{2}$ mitigation with microalgae systems," Energy Conversion and Management, vol. 38, no. 1, pp. S475S479, 1997.
[13] M. J. Haas, K. M. Scott, T. A. Foglia, and W. N. Marmer, “The general applicability of in situ transesterification for the production of fatty acid esters from a variety of feedstocks," Journal of the American Oil Chemists' Society, vol. 84, no. 10, pp. 963970, 2007.

[14] M. D. Supardan, "The use of ultrasonic method for transesterification of used cooking oil," Journal of Chemical and Environmental Engineering, vol. 8, no. 1, pp. 11-16, 2011.

[15] R. E. Armenta, M. Vinatoru, A. M. Burja, J. A. Kralovec, and C. J. Barrow, "Transesterification of fish oil to produce fatty acid ethyl esters using ultrasonic energy," Journal of the American Oil Chemists' Society, vol. 84, no. 11, pp. 1045-1052, 2007.

[16] C. Stavarache, M. Vinatoru, R. Nishimura, and Y. Maeda, "Fatty acids methyl esters from vegetable oil by means of ultrasonic energy," Ultrasonics Sonochemistry, vol. 12, no. 5, pp. 367-372, 2005.

[17] E. Crabbe, C. Nolasco-Hipolito, G. Kobayashi, K. Sonomoto, and A. Ishizaki, "Biodiesel production from crude palm oil and evaluation of butanol extraction and fuel properties," Process Biochemistry, vol. 37, no. 1, pp. 65-71, 2001.

[18] K. S. Suslick, Y. Didenko, M. M. Fang et al., "Acoustic cavitation and its chemical consequences," Philosophical Transactions of the Royal Society A, vol. 357, no. 1751, pp. 335-353, 1999.

[19] L. H. Thompson and L. K. Doraiswamy, "Sonochemistry: science and engineering," Industrial and Engineering Chemistry Research, vol. 38, no. 4, pp. 1215-1249, 1999.

[20] Seafdec, Prawn Hatchery Design and Operational, Aquaculture Extention Manual 9, Aquaculture Department, Tigbauan, Philippines, 1985.

[21] S. Rasoul-Amini, N. Montazeri-Najafabady, M. A. Mobasher, S. Hoseini-Alhashemi, and Y. Ghasemi, "Chlorella sp.: a new strain with highly saturated fatty acids for biodiesel production in bubble-column photobioreactor," Applied Energy, vol. 88, no. 10, pp. 3354-3356, 2011.

[22] M. Shiho, M. Kawachi, K. Horioko et al., "Business evaluation of a green microalgae Botryococcus braunii oil production system," Procedia Environmental Sciences, vol. 15, pp. 90-109, 2012.

[23] H. Y. El-Kassas, "Growth and fatty acid profile of the marine microalga Picochlorum Sp. grown under nutrient stress conditions," Egytian Journal of Aquatics Research, vol. 39, pp. 233-239, 2013.

[24] I. Aziz, S. Nurbayati, and B. Ulum, "Production of biodiesel from cooking oil by esterification and transesterification method," Valensi, vol. 2, no. 3, pp. 443-448, 2011.

[25] I. H. S. Nirwana, Effect of Stirring Speed for Biodiesel Production from Jatropha Oil (Jatropha curca L.) by Using Catalysts Abu Tandan Sawit, Research Institue, Riau University, Riau, Indonesia, 2012.

[26] G. Knothe, "Dependence of biodiesel fuel properties on the structure of fatty acid alkyl esters," Fuel Processing Technology, vol. 86, no. 10, pp. 1059-1070, 2005.

[27] M. M. Azam, A. Waris, and N. M. Nahar, "Prospects and potential of fatty acid methyl esters of some non-traditional seed oils for use as biodiesel in India," Biomass and Bioenergy, vol. 29, no. 4, pp. 293-302, 2005. 


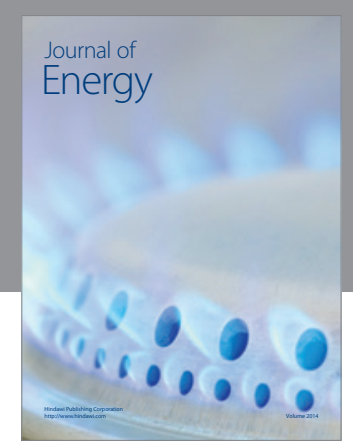

Journal of

Industrial Engineering
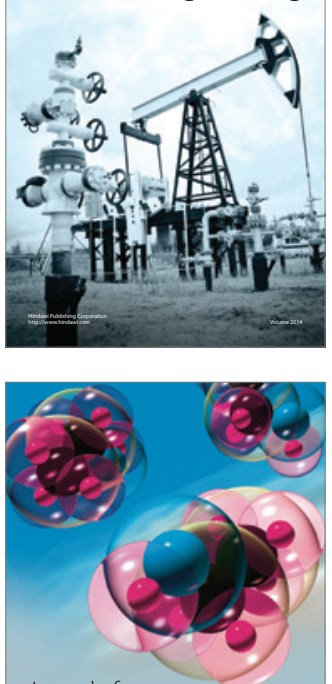

Fuels
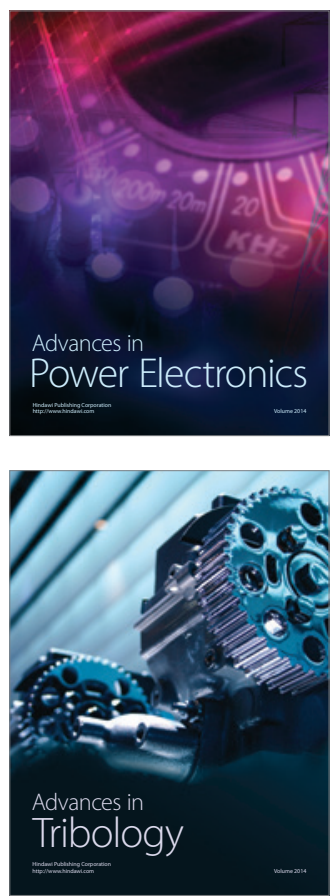

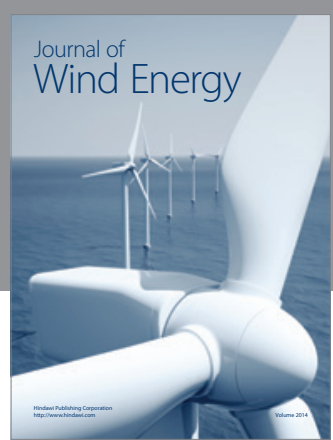

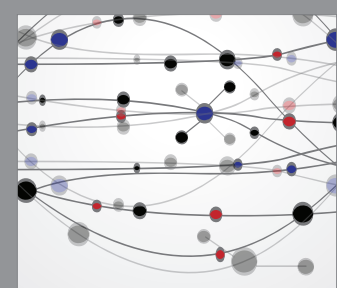

The Scientific World Journal

Submit your manuscripts at http://www.hindawi.com

Journal of

Structures
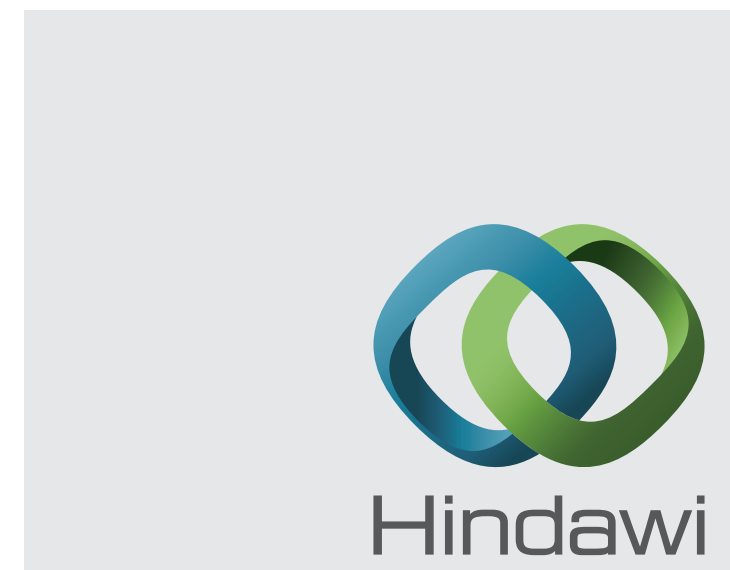

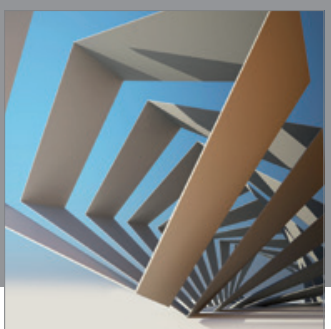

Rotating

Machinery
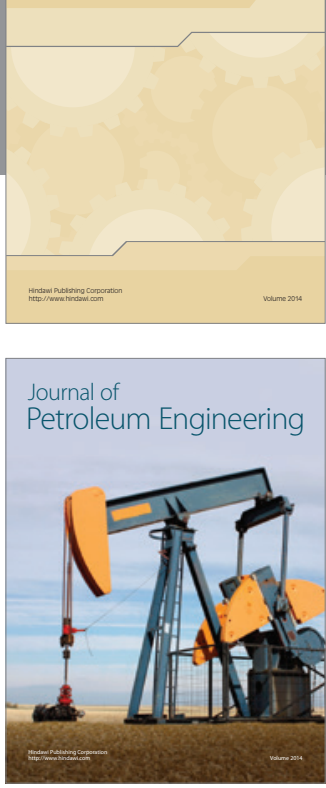

Journal of

Solar Energy
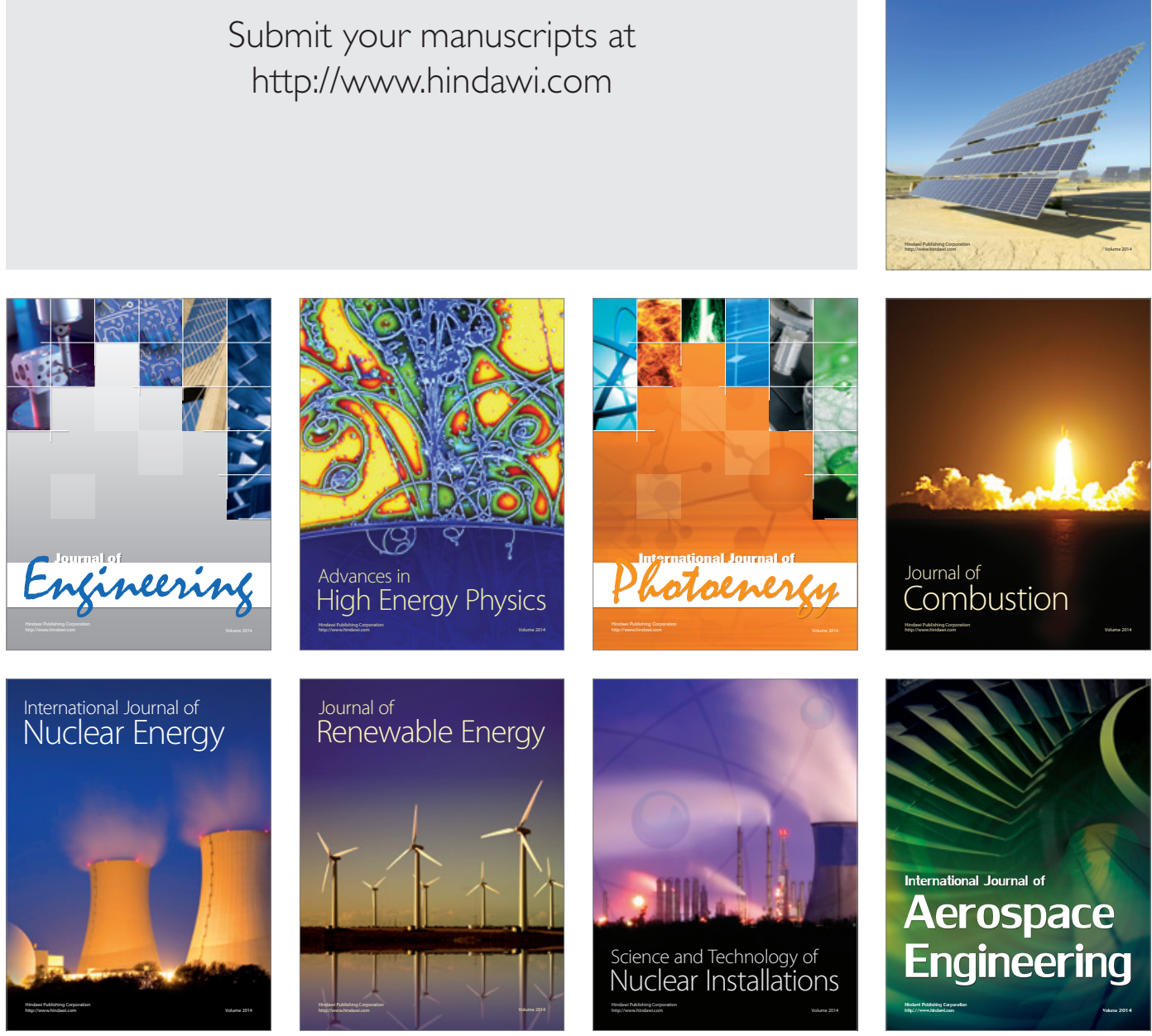